\title{
Yaz aylarında Batı Anadolu'nun bazı dağ göllerinin (Denizli-Muğla) fitoplankton kompozisyonu ve trofik durum indeksi değerleri
}

\section{Summer phytoplankton composition and trophic state index values of some mountain lakes in Western Anatolia (Denizli-Muğla)}

\author{
Haşim Sömek $^{1^{*}}$ • M. Ruşen Ustaoğlu² \\ 1 İzmir Kâtip Çelebi Üniversitesi, Su Ürünleri Fakültesi, Su Ürünleri Temel Bilimler Bölümü, İcsular Biyolojisi Anabilim Dalı, Çiğli-lzmir \\ 2 Ege Üniversitesi, Su Ürünleri Fakültesi, Su Ürünleri Temel Bilimler Bölümü, İçsular Biyolojisi Anabilim Dalı, Bornova-Izmir \\ *Corresponding author: hasim.somek@ikc.edu.tr
}

How to cite this paper:

Sömek, H. \& Ustaoğlu M.R. (2016). Summer phytoplankton composition and trophic state index values of some mountain lakes in Western Anatolia (Denizli-

Muğla) (in Turkish with English abstract). Ege Journal of Fisheries and Aquatic Sciences, 33(2): 121-128 . doi: 10.12714/egejfas.2016.33.2.05

\begin{abstract}
Öz: Batı Anadolu'nun dağlık alanlarında yer alan Saklıgöl, Karagöl, Gökçeova Göleti, Kartal Gölü olmak üzere 4 gölden fitoplankton ve yüzey suyu örneklemeleri yapılmıştır. Bu göllere kış ulaşımının zor olmasından dolayı, 2009, 2010, 2011 yıllarının yaz ayları örnekleme zamanı olarak tercih edilmiştir. Yapılan incelemeler sonucunda, Cyanobacteria (5), Bacillariophyta (22), Ochrophyta (3), Chlorophyta (16), Charophyta (6), Miozoa (3) ve Euglenophyta (4) divizyolarına dahil 59 takson teşhis edilmiştir. Saklıgöl'den 23, Gökçeova Göleti'nden 26, Kartal Göl'ünden 21 ve Karagöl'den 24 fitoplankton taksonu saptanmıştır. Sonuç olarak, göllerin fitoplankton kompozisyonu ve diğer bazı ekolojik değerleri, inceleme yapılan göllerin verimlilik durumunun oligotrofik olduğunu göstermektedir. Bu çalışmada, Türkiye'nin dağ göllerinin fitoplankton kompozisyonu ve limnolojisi hakkındaki bilgilere katkılar sağlanması amaçlamıştır.
\end{abstract}

Anahtar kelimeler: Dağ Gölleri, fitoplankton, çevresel parametreler, trofik durum indeksi

Abstract: : Phytoplankton and surface water samples were taken from four lakes (Lake Saklıgöl, Lake Karagöl, Gökçeova Pond, Lake Kartal) located in the mountainous areas of western Anatolia. Because of difficult access to the lakes during winter season, summer months of the years 2009,2010 and 2011 were preferred as sampling time. As a result of the investigations, 59 taxa belonging to Cyanobacteria (5), Bacillariophyta (22), Ochrophyta (3), Chlorophyta (16), Charophyta (6), Miozoa (3) and Euglenophyta (4) divisions were identified. 23 taxa from Lake Saklıgöl, 26 taxa from Gökçeova Pond, 21 taxa from Lake Kartal and 24 taxa from Lake Karagöl were determined. As a consequence, phytoplankton composition and some other ecological characteristics indicate that the trophic status of the investigated lakes is oligotrophic. In this study, it was aimed to provide contributions to the knowledge on phytoplankton composition and limnology of mountain lakes in Turkey.

Keywords: Mountain lakes, phytoplankton, environmental parameters, trophic state index

\section{Gíriş}

Dağ gölleri benzersiz doğa güzellikleri yanında barındırdıkları biyolojik çeşitlilik nedeniyle korunması gerekl olan ve oldukça özel sucul ekosistemlerdir. Genel olarak dağ gölleri, botanikçilerin vejetasyonun yüksekliğe bağı dağılımı temel alınarak, alpin göller (ağaç sınırının üstü), subalpin göller (bodur çalı ve nemli çayırlıklar) ve dağ gölleri (yüksek boylu ağaçlar) olarak sınıflandırılmaktadır (Pechlaner, 1971; Sarı, 2010). Yüksek ve dağlık alanlarda bulunan bu göller, ova gölleri ile kıyaslandığında nispeten küçük olup, insan kaynaklı tarımsal veya evsel kirleticilerden hemen hemen hiç etkilenmezler. Diğer taraftan, bilinen ötrofikasyon süreçlerinden veya atmosferik olmayan kirleticilerden çoğunlukla korunan dağ gölleri, sanayileşmenin hızla artıı̆ı son 20 yılda, havadan gelen asitler ve nutriyentlerden etkilenmektedirler (Anonim, 1999). Sahip oldukları kendine özgü iklimsel (yüksek irtifa, düşük hava (c) Published by Ege University Faculty of Fisheries, Izmir, Turkey sıcaklıkları, yüksek U.V. ışık, kuvvetli rüzgarlar, donma ve kar yağışları vb.) ve fiziko-kimyasal koşullar (asitleşme) nedeniyle bu göller uzun zamandır limnologların oldukça ilgisini çekmektedir (Heinonen, 1980; Willén vd., 1990; Tolotti, 2001).

Göllere ulaşımın zor olması ve yılın büyük bir bölümünde buzla kaplı olması nedeniyle, ülkemizde yüksek dağ göllerinin limnolojisi üzerine gerçekleştirilmiş sınırlı sayıda çalışma bulunmaktadır. Bunlardan bazıları, Kaçkar sıra dağlarında yer alan alpin ve subalpin göllerde (Şahin, 2000, 2001; Yıldız vd., 2012) bazıları da Toros dağlarında yüksek dağ göllerinde gerçekleştirilen çalışmalardır (Balık vd., 2003; Ustaoğlu vd., 2004, 2005; Yıldız vd., 2005). Daha düşük yükseltilerde bulunan dağ göllerinde ise fitoplankton üzerine yapılmış olan az sayıda çalışma vardır (Cirik ve Cirik, 1989; Kolaylı ve Şahin, 
2007; Sömek ve Balık, 2009). Bu çalışma ile dağ göllerinin fitoplankton kompozisyonu ve limnolojisi üzerine yapılmış çalışmalara bir yenisi eklenerek, Türkiye'de yer alan bu tip sucul ekosistemlerin biyoçeşitliliğinin ve ekolojilerinin ortaya çıkarılmasına katkı sağlanması amaçlanmıştır.

\section{MATERYAL VE YÖNTEM}

Batı Anadolu'nun dağlık alanlarında yer alan Saklıgöl

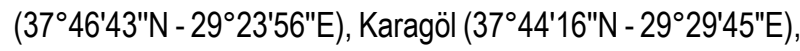
Gökçeova Göleti $\left(37^{\circ} 03^{\prime} 49^{\prime \prime N}\right.$ - 28 $\left.8^{\circ} 48^{\prime} 24^{\prime \prime E}\right)$, Kartal Gölü $\left(37^{\circ} 05^{\prime} 50^{\prime \prime} \mathrm{N}-28^{\circ} 51^{\prime} 01^{\prime \prime E}\right)$ olmak üzere 4 gölden örnekleme çalışmaları yapılmış olup, bu bölgelere kış boyunca ulaşımın zor olmasından dolayı 2009, 2010, 2011 yıllarının sadece yaz aylarında gidilebilmiştir (Şekil 1). Fitoplankton örneklemeleri 55 $\mu \mathrm{m}$ göz açıklı̆ına sahip Hydrobios plankton kepçesi kullanılarak gerçekleştirilmiştir. Toplanan örnekler son konsantrasyonları \% 4 olacak şekilde formaldehit ile tespit edilmiştir.
Su derinliği ve ışık geçirgenliği ölçümlerinde, $30 \mathrm{~cm}$ çapında standart Secchi diski kullanılışıtır. Su sıcaklığı, elektrik iletkenliği için YSI 30 model SCT metre, çözünmüş oksijen için WTW Oxi 330 model oksijen metre ve $\mathrm{pH}$ ölçümleri için WTW pH 330 model pH metre kullanılmıştır. Klorofil-a tayini ise fluorometrik olarak (Turner $10 \mathrm{AU}$ Fluorometre) yapılmıştır. Göllerin trofik durumunu saptamak için Trofik Durum İndeksi (TDi) "Trophic State Index (TSI)" yönteminden yararlanılmıştır. Indeks sonuçları Secchi derinliği ve Klorofil-a ölçümlerinin ortalama değerleri kullanılarak aşağıda verilen formüllere göre hesaplanmıştır (Carlson ve Simpson, 1996).

$$
\begin{aligned}
& \text { TDi (SD) = 60-14341 In(SD) (SD :Secchi Derinliği ,m) } \\
& \text { TDi (KIf-a) = 9,81 In(KIf-a) + 30,6 (Klf-a :Klorofil-a, } \mu \text { g/L). }
\end{aligned}
$$

Fitoplankton türlerinin tayin edilmesinde çeşitli araştırmacıların monografi düzeyindeki eserlerinden yararlanılmışır (Bourrelly, 1966, 1968, 1970; Philipose, 1967; Sims, 1996; John vd.,, 2003; Komárek ve Zapomelova, 2007). Teşhis edilen taksonların sistematik hiyerarşideki güncel konumları algaebase.org internet sitesinden kontrol edilmiştir (Guiry ve Guiry, 2016).

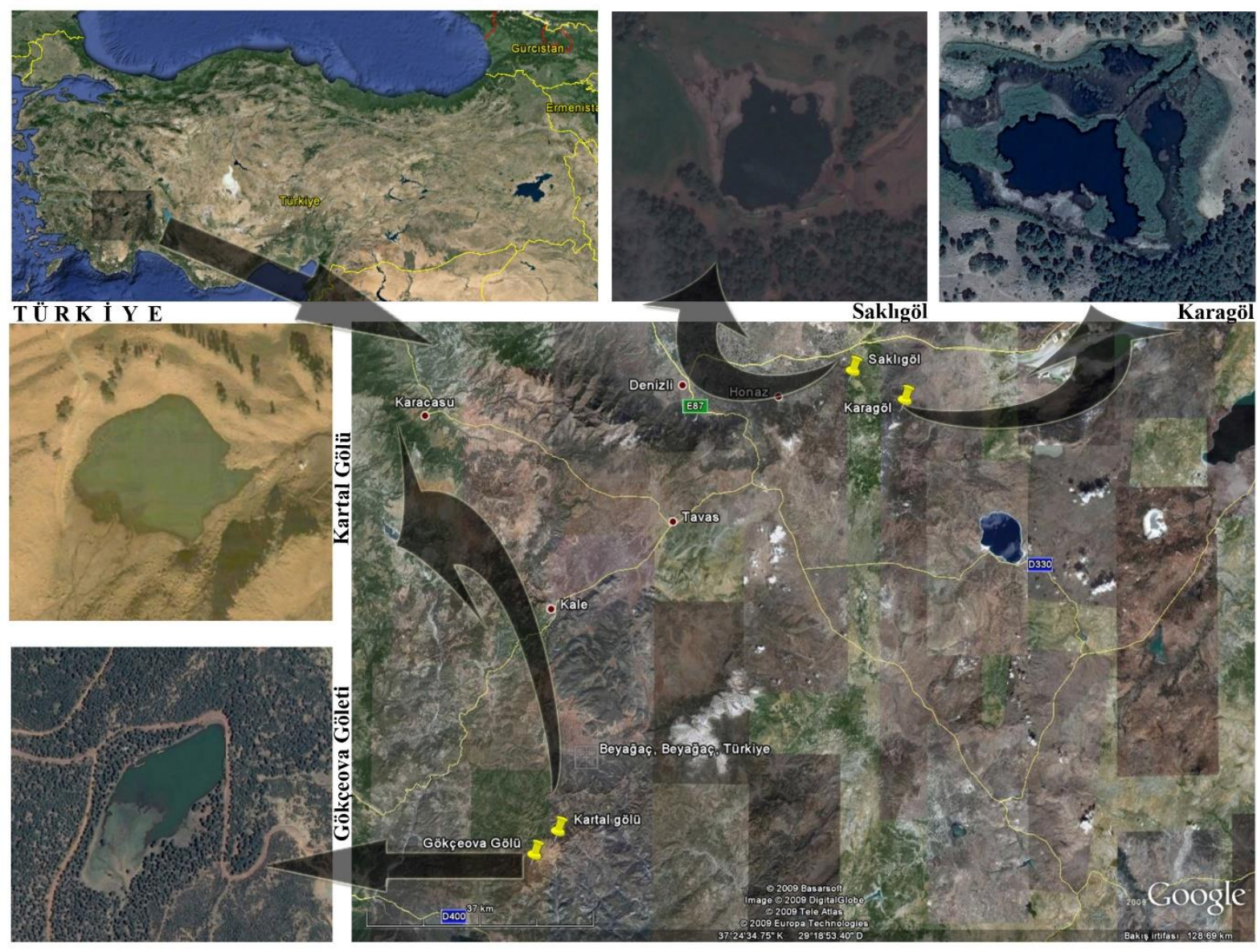

Şekil 1. Çalışma alanları

Figure 1. The study areas 


\section{BULGULAR}

Göller arasında deniz seviyesinden en yüksekte olan Kartal Gölü (1885 m)'dür. Bunu sırasıyla Gökçeova Göleti (1755 m), Karagöl (1248 m) ve Saklıgöl (953 m) takip etmektedir. Saklıgöl $8 \mathrm{~m}$ ve Karagöl 1,7 m maksimum derinliğindedir ve su bitkileri barındırmaktadır. Gökçeova Göleti ve Kartal Gölü'nde ise sırasıyla 4,8 ve 1,2 m maksimum derinlik değerleri tespit edilmiştir. Göllerde örnekleme dönemi boyunca, Işık geçirgenliği değerleri 60-330 cm arasında, yüzey suyu sıcaklık değerleri 17,9 ile $27,5^{\circ} \mathrm{C}$ arasında, pH değerleri 6,63 ile 9,06 arasında, çözünmüş oksijen ve oksijen doygunluğu değerleri sırasıyla 3,3 ile $8,6 \mathrm{mg} / \mathrm{L}$ ve $\% 48$ ile 124 arasında, tuzluluk değerleri \%o 0,1 ile 0,5 arasında, iletkenlik değerleri 84 ile 1039 $\mu \mathrm{S} 25^{\circ} \mathrm{C}$ arasında, klorofil-a değerleri 0.383 ile $8.065 \mu \mathrm{g} / \mathrm{L}$ arasında değişim göstermiş olup, çevresel parametreler ile ilgili ayrıntılar Tablo 1'de verilmiştir.

Tablo 1. Çalışma alanlarındaki bazı çevresel parametre değerleri

Table 1. Some environmental parameter values in the study areas

\begin{tabular}{|c|c|c|c|c|c|c|}
\hline \multirow{2}{*}{ :号 } & \multirow[b]{2}{*}{ PARAMETRELER } & \multicolumn{2}{|c|}{2009} & \multirow{2}{*}{$\begin{array}{c}2010 \\
\text { TEMMUZ }\end{array}$} & \multirow{2}{*}{$\begin{array}{c}2011 \\
\text { TEMMUZ }\end{array}$} & \multirow[b]{2}{*}{ ORTALAMA } \\
\hline & & HAZIRAN & AĞUSTOS & & & \\
\hline \multirow[b]{3}{*}{ 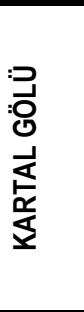 } & Işık Geçirgenliği (cm) & 120 & 100 & 110 & 90 & 105,0 \\
\hline & Sicaklık $\left({ }^{\circ} \mathrm{C}\right)$ & 18,0 & 21,5 & 23,7 & 17,9 & 20,28 \\
\hline & $\begin{array}{l}\text { pH } \\
\text { Çözünmüş Oksijen (mg/L) } \\
\text { Ç,Oksijen Doygunluğu (\%) } \\
\text { Tuzluluk }(\% 0 \mathrm{~S}) \\
\text { Illetkenlik }\left(\mu \mathrm{S}_{\left.25^{\circ} \mathrm{C}\right)}\right. \\
\text { Klorofil-a }(\mu \mathrm{g} / \mathrm{L})\end{array}$ & $\begin{array}{c}8,45 \\
8,5 \\
114 \\
0,1 \\
84 \\
8,065 \\
\end{array}$ & $\begin{array}{c}9,06 \\
8,6 \\
124 \\
0,1 \\
109 \\
1,362 \\
\end{array}$ & $\begin{array}{c}8,58 \\
8,6 \\
124 \\
0,1 \\
102 \\
0,383 \\
\end{array}$ & $\begin{array}{c}8,25 \\
6,0 \\
96 \\
0,1 \\
100 \\
1,159 \\
\end{array}$ & $\begin{array}{c}8,59 \\
7,93 \\
114,5 \\
0,1 \\
98,75 \\
2,74 \\
\end{array}$ \\
\hline \multirow{8}{*}{ : } & Işık Geçirgenliği (cm) & 170 & 90 & 90 & 110 & 115,0 \\
\hline & Sıcaklık $\left({ }^{\circ} \mathrm{C}\right)$ & 19,0 & 20,5 & 23,3 & 25,1 & 21,98 \\
\hline & $\mathrm{pH}$ & 7,99 & 8,49 & 6,63 & 8,51 & 7,91 \\
\hline & Çözünmüş Oksijen (mg/L) & 7,2 & 6,7 & 5,7 & 4,9 & 6,13 \\
\hline & Ç,Oksijen Doygunluğu (\%) & 95 & 93 & 86 & 90 & 91,0 \\
\hline & Tuzluluk (\%o S) & 0,1 & 0,1 & 0,1 & 0,1 & 0,1 \\
\hline & İletkenlik $\left(\mu \mathrm{S}_{25^{\circ} \mathrm{C}}\right)$ & 211 & 249 & 229 & 249 & 234,50 \\
\hline & Klorofil-a ( $\mu \mathrm{g} / \mathrm{L})$ & 2,069 & 1,490 & 1,441 & 4,442 & 2,360 \\
\hline \multirow{8}{*}{ 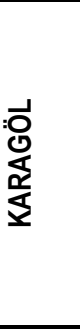 } & Işık Geçirgenliği (cm) & 60 & 80 & * & * & 70,00 \\
\hline & Sıcaklık $\left({ }^{\circ} \mathrm{C}\right)$ & 25,6 & 24,0 & 25,9 & * & 25,17 \\
\hline & $\mathrm{pH}$ & 7,89 & 8,05 & 8,02 & * & 7,99 \\
\hline & Çözünmüş Oksijen (mg/L) & 3,3 & 5,6 & 4,8 & * & 4,57 \\
\hline & Ç,Oksijen Doygunluğu (\%) & 48 & 77 & 73 & * & 66,0 \\
\hline & Tuzluluk (\%o S) & 0,4 & 0,4 & 0,4 & * & 0,4 \\
\hline & İletkenlik $\left(\mu \mathrm{S}_{25^{\circ} \mathrm{C}}\right)$ & 723 & 792 & 748 & * & 754,3 \\
\hline & Klorofil-a $(\mu \mathrm{g} / \mathrm{L})$ & 5,645 & 4,780 & 3,249 & * & 4,560 \\
\hline \multirow{8}{*}{ 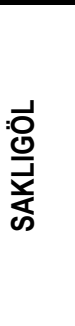 } & Işık Geçirgenliği (cm) & 330 & 210 & 190 & 240 & 242,5 \\
\hline & Sıcaklık $\left({ }^{\circ} \mathrm{C}\right)$ & 22,5 & 23,0 & 25,1 & 27,5 & 24,53 \\
\hline & $\mathrm{pH}$ & 8,25 & 8,40 & 8,42 & 8,34 & 8,35 \\
\hline & Çözünmüş Oksijen (mg/L) & 5,2 & 5,7 & 5,5 & 4,3 & 5,18 \\
\hline & Ç,Oksijen Doygunluğu (\%) & 68 & 73 & 77 & 77 & 73,75 \\
\hline & Tuzluluk (\%o S) & 0,5 & 0,5 & 0,5 & 0,5 & 0,5 \\
\hline & İletkenlik $\left(\mu \mathrm{S}_{25^{\circ} \mathrm{C}}\right)$ & 960 & 1039 & 968 & 1038 & 1001,2 \\
\hline & Klorofil-a $(\mu \mathrm{g} / \mathrm{L})$ & 2,807 & 1,178 & 0,770 & 3,889 & 2,160 \\
\hline
\end{tabular}

( ${ }^{*}$ Ölçüm yapılamadı)

( ${ }^{*}$ The measurement could not be made)

Ege bölgesinin Güney doğusunda bulunan Saklıgöl, Gökçeova Göleti, Kartal Gölü ve Karagöl'deki ortalama Secchi derinliği (Işık geçirgenliği) ve klorofil-a ölçümlerinden hesaplanan TDi (SD) sonuçları 47,3 ile 59,3 arasında, TDi (Klorofil-a) sonuçları 38,1 ile 45,5 arasında, TDi (Ortalama) ise 42,7 ile 55,5 arasında değişim göstermiştir (Şekil 2). 


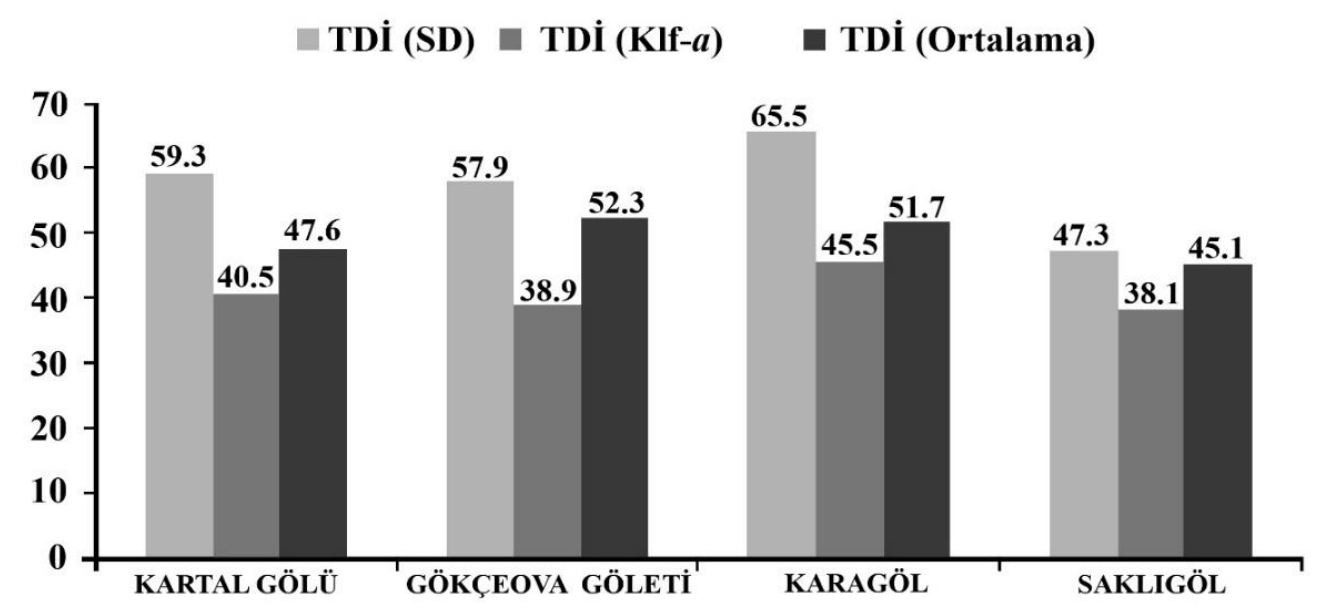

Şekil 2. Çalışma alanlarında hesaplanan Trofik Durum Indeksi değerleri

Figure 2. Trophic State Index values calculated in the study areas

Araştırılan göllerde yapılan taksonomik incelemeler sonucunda fitoplanktonik organizmalardan 6 divizyoya ait 59 takson tespit edilmiştir (Tablo 2). Taksonların 5'i Cyanobacteria, 25’i Bacillariophyta, 3'ü Ochrophyta, 16'sı
Chlorophyta, 6'sı Charophyta, 4'ü Euglenophyta, 3'ü Miozoa divizyolarına dahildir. Bu çalışmada Saklıgöl'den 23, Gökçeova Göleti'nden 26, Kartal Göl'ünden 21 ve Karagöl'den 24 takson saptanmıştır.

Tablo 2. Çalışma alanlarındaki göllerin fitoplankton kompozisyonu (a: Saklıgöl; b:Gökçeova Göleti; c:Kartal Gölü; d: Karagöl) Table 2. Phytoplankton composition of lakes in the study area (a: Lake Saklıg̈l; b:Gökçeova Pond; c: Lake Kartal; d: Lake Karagöl)

\begin{tabular}{|c|c|c|c|}
\hline Cyanobacteria & 2009 & 2010 & 2011 \\
\hline Anabaena sp. & $a$ & & $\mathrm{a}$ \\
\hline Dolichospermum affine (Lemmermann) Wacklin, Hoffmann \&.Komárek & & b & \\
\hline Gomphosphaeria aponina Kützing & & d & \\
\hline Pseudanabaena catenata Lauterborn & d & & \\
\hline Spirulina nordstedtii Nordstedt ex Gomont & $d$ & & \\
\hline \multicolumn{4}{|l|}{ Bacillariophyta } \\
\hline Amphora ovalis (Kützing) Kützing & & C & c \\
\hline Cocconeis placentula Ehrenberg & & a & \\
\hline Cyclotella ocellata Pantocsek & & a & $\mathrm{ac}$ \\
\hline Cymbella cistula (Ehrenberg) Kirchner & $a b$ & $b d$ & $a b$ \\
\hline Cymbella helvetica Kützing & $\mathrm{C}$ & $c$ & $\mathrm{C}$ \\
\hline Cymbopleura inaequalis (Ehrenberg) Krammer & & & a \\
\hline Epithemia adnata (Kützing) Brébisson & & $d$ & a \\
\hline Epithemia sorex Kützing & c & & a \\
\hline Fragilariforma virescens (Ralfs) Williams \& Round & $b c$ & & \\
\hline Fragilaria crotonensis Kitton & bc & $b$ & $b$ \\
\hline Hantzschia amphyoxis (Ehrenberg) Grunow & $\mathrm{b}$ & & \\
\hline Navicula radiosa Kützing & $\mathrm{cd}$ & $\mathrm{cd}$ & \\
\hline Neidium ampliatum (Ehrenberg) Krammer in Krammer \& Lange-Bertalot & & $\mathrm{c}$ & c \\
\hline Nitzschia obtusa W.Smith & a & & \\
\hline Pinnularia maior (Kützing) Cleve & & & c \\
\hline Pinnularia mesolepta (Ehrenberg) W.Smith & b & & \\
\hline Pinnularia subviridis A.Cleve & $\mathrm{b}$ & $c$ & \\
\hline Rhopalodia gibba (Ehrenberg) Otto Müller & b & bd & \\
\hline Stauroneis anceps Ehrenberg & $c$ & $c$ & $c$ \\
\hline Ulnaria acus (Kützing) Aboal & $a b$ & $a b$ & a \\
\hline Ulnaria capitata (Ehrenberg) Compère & ad & a & $c$ \\
\hline Ulnaria ulna (Nitzsch) Compère & bcd & bcd & $a b c$ \\
\hline Ochrophyta & & & \\
\hline
\end{tabular}




\begin{tabular}{lcc}
\hline Dinobryon divergens O.E.Imhof & $\mathrm{d}$ & $\mathrm{d}$ \\
Dinobryon sertularia Ehrenberg & $\mathrm{d}$ \\
Dinobryon sociale (Ehrenberg) Ehrenberg & $\mathrm{b}$ & $\mathrm{b}$ \\
\hline Chlorophyta & $\mathrm{d}$ & $\mathrm{bd}$ \\
\hline Acutodesmus obliquus (Turpin) Hegewald \& Hanagata & & $\mathrm{b}$ \\
Ankistrodesmus falcatus (Corda) Ralfs & $\mathrm{d}$ \\
Botryococcus braunii Kützing & $\mathrm{c}$ \\
Closteriopsis acicularis (Chodat) Belcher \& Swale & $\mathrm{d}$ \\
Closteriopsis longissima (Lemmermann) Lemmermann & \\
Desmodesmus abundans (Kirchner) Hegewald & $\mathrm{a}$ \\
Desmodesmus communis (Hegewald) Hegewald & $\mathrm{c}$ \\
Desmodesmus opoliensis (Richter) Hegewald & $\mathrm{b}$ \\
Monoraphidium irregulare (G.M.Smith) Komárková-Legnerová & $\mathrm{bc}$ & $\mathrm{bd}$ \\
Mucidosphaerium pulchellum (Wood) Bock, Proschold \& Krienitz & $\mathrm{b}$ \\
Pandorina morum (O.F.Müller) Bory & $\mathrm{b}$ \\
Pediastrum duplex Meyen & $\mathrm{b}$ \\
Pseudopediastrum boryanum (Turpin) Hegewald in Buchheim et al. & $\mathrm{bc}$ \\
Scenedesmus nanus Chodat & $\mathrm{b}$ \\
Tetraedron minutum (A.Braun) Hansgirg & $\mathrm{b}$ & $\mathrm{b}$ \\
\hline & $\mathrm{a}$ & $\mathrm{b}$ \\
\hline
\end{tabular}

\section{TARTIŞMA VE SONUÇ}

Incelenen göllerde saptanan derinlik değerlerine göre, Saklıgöl $(8 \mathrm{~m})$ hariç, diğerlerinin nispeten sığ göller oldukları anlaşılmıştır. Yüzey suyu sıcaklıkları, diğerlerine oranla daha yüksekte bulunan Kartal Gölü ve Gökçeova Göletinde oldukça düşüktür. Bu durum söz konusu göllerin deniz seviyesinden yüksekliklerinin beraberinde getirdiği iklim koşullarının bir sonucudur. Çalışma döneminde ortalama pH değerleri 7,918,59 arasında değişen bu göllerin hafif alkali karakterli oldukları saptanmıştır. Alg hücrelerinin fotosentezde kullandıkları $\mathrm{CO}_{2}$ 'in membran yüzeyinden difüzyon yolu ile geçmesi $\mathrm{pH}$ 8-10 değerleri arasında daha kolay olduğu, bunun sonucunda fotosentez hızının da arttığı bildirilmiştir (Bozniak ve Kenedy, 1968). Buradan, incelenen dağ göllerinin sahip olduğu hafif alkali ortamın alg gelişimi için kısmen uygun olduğu sonucuna varılabilir. Araştırılan göller arasında bazı dönemlerde oldukça düşük çözünmüş oksijen değerleri tespit edilmiştir. Derin göllerde, oksijen tüketilen trofolitik reaksiyonlar geniş hipolimniyon tabakasında gerçekleşirken, sığ göllerde su kolonunun tamamında gerçekleşmesi nedeniyle, sığ göllerin aynı yüzey alanına sahip derin göllere göre daha az oksijen depoladıkları bilinmektedir (Lampert ve Sommer, 2007).

Araştırılan göllerin klorofil-a değerlerinin Gökçeova Göletinde 1,44-4,44 $\mu \mathrm{g} / \mathrm{L}$ arasında, Kartal Gölünde, 0,38-8,06 $\mu \mathrm{g} / \mathrm{L}$ arasında, Saklıgöl'de 0,77-2,80 $\mu \mathrm{g} / \mathrm{L}$ arasında, Karagöl'de 3,29-5,64 $\mu \mathrm{g} / \mathrm{L}$ arasında değişim gösterdiği saptanmıştır. Sakamoto (1966) klorofil-a derecesini ötrof göller için 5-140 $\mu \mathrm{g} / \mathrm{L}$, mezotrof göller için 1-15 $\mu \mathrm{g} / \mathrm{L}$ ve oligotrof göller için 0,3$2,5 \mu \mathrm{g} / \mathrm{L}$ olarak bildirmiştir.

Carlson (1977) tarafından geliştirilen Trofik Durum İndeksi günümüzde gerçekleştirilen birçok limnoloiik araştırmada lentik habitatların verimliliğinin belirlenmesinde kullanılmaktadır (Katip vd., 2015; Cigagna vd., 2016). TDi değerleri <30 veya 30-40 ise oligotrof, 40-50 ise mezotrof, $50-70$ ise ötrof ve 70-80 veya $>80$ ise hiperötrof olduğu bildirilmiştir (Carlson ve
Simpson, 1996). Araştırma alanımızdaki göllerde Secchi disk ölçümleri sonucunda elde edilen ışık geçirgenliği değerleri oligotrofik göller ile kıyaslandığında nispeten düşüktür (Vollenweider ve Kerekes, 1982). Benzer şekilde klorofil-a derişimlerinin de düşük tespit edilmiş olması, ışık geçirgenliğindeki azlığın fitoplankton kaynaklı olmadığını göstermektedir. Sığ göl ve göletlerde su hareketleri sonucunda bentik materyalin su kolonuna taşındığı bilinmektedir (Round, 1973). Bu durumda sığ göllerde sadece ışık geçirgenliği değerleri dikkate alınarak yapılan trofik durum saptanması yanılıcı olacaktır. Bu araştırmada Klorofil-a ve Secchi diski ölçüm değerlerinden yararlanılarak hesaplanan TDi ve ortalama TDI değerlerine göre göller oligotrofik durumun sınırında veya çok az üzerinde tespit edilmiştir.

Cyanobacteria üyeleri ülkemizde daha çok ötrof göllerde yaygın olarak tespit edilmiş olup (Cirik-Altındağ, 1982; Albay vd., 2003; Sömek ve Balık, 2009), yaz aylarında besleyici maddelerce zengin ve ötrof göllerde aşırı çoğalmalar gösterebilirler (Vaitomaa, 2006). Bu araştırmada ise Cyanobacteria üyelerinden çok az takson saptanmıştır. Bu taksonlara ülkemizde yer alan iç su ekosistemlerinde de sıklıkla rastlanılmaktadır (Karacaoğlu vd., 2004; Taş ve Gönülol, 2007; Çelekli vd., 2007).

İncelenen göllerin fitoplanktonunda diyatomelerin takson sayısı yönünden diğerlerine oranla fazla olması dikkat çekicidir ve bunların çoğunluğunu bentik diyatomeler oluşturmaktadır. Nispeten sığ, küçük alana sahip göl ve göletlerde çeşitli su hareketleri nedeniyle bentik orijinli pennat diyatomelerin pelajik bölgeye taşındıkları bilinmektedir (Round, 1973). Buna benzer durumlar ülkemiz göllerinde de saptanmıştır (Şen vd., 2001; Akköz ve Güler, 2004). Bu araştırmada, en fazla diyatome türünün en sığ göl olan Kartal Gölü'nde tespit edilmiş olması bu durumu desteklemektedir. Araştırma alanımızdaki göllerde sıklıkla tespit edilen Ulnaria acus türünün besleyici mineral maddelerce zengin ve turbiditesi yüksek sularda bulunduğu, $U$. 
ulna türünün ise ötrof göllerin karakteristik türlerinden olduğu bildirilmiştir (Hustedt, 1930; Reynolds vd., 2002). Bu araştırmada tespit edilen Bacillariophyta üyelerinin çoğunun çevresel değişkenlere toleransı yüksektir ve ülkemizin oligotrofik, mezotrofik veya ötrofik olduğu bilinen birçok göl ve akarsularında yaygın olarak dağılım göstermektedir (Aysel, 2005).

Chlorophyta bölümü araştırma alanımızda ikinci derecede en fazla taksonla temsil edilen fitoplankton grubu olmuştur. Chlorophyta bölümünün tamamını Chlorococcales üyeleri oluşturmuştur. Bu durum ülkemizde yer alan bir çok mezotrofik ve ötrofik göllerin fitoplankton kompozisyonu ile benzerlik göstermektedir (Gönülol ve Obalı, 1998; İşbakan-Taş vd., 2002; Ongun-Sevindik, 2010). Chlorococcales üyelerinin bulunuşu oligotrofik devreden ötrofik devreye geçiş olarak kabul edilmiştir (Hutchinson, 1957). Bunlardan Monoraphidium irregulare araştırma alanımızdaki bütün göllerde tespit edilmiştir. Monoraphidium türlerinin oligotrofik ve mezotrofik göllerde baskın olduğu bilinmektedir (Legnerova, 1965). Araştırma alanımızda sıklıkla tespit edilen diğer Chlorococcales üyelerinden olan Scenedesmus ve Pediastrum türlerine ülkemizdeki oligomezotrofik rezervuarlarda ve ötrofik göllerde bol olarak rastlanmıştır (Aykulu vd.,1983, İşbakan-Taş vd., 2002; Kıvrak ve Gürbüz, 2005; Ongun-Sevindik, 2010).

Charophyta bölümünden ise 6 takson tespit edilmiş olup, bunların çoğunluğunu Cosmarium ve Closterium cinslerine ait türler oluşturmaktadır. Bu cinslere ait türlere ülkemizdeki birçok oligotrofik ve mezotrofik göllerde rastlanmaktadır (Akköz ve Güler, 2004; Baykal vd., 2004; Karacaoğlu vd., 2004; Şahin ve Akar, 2007). Palmer (1980) Desmidiaceae türlerinin çoğunun oligotrofik sularda, çok azının ise ötrofik sularda bulunabildiğini bildirmiştir. İpliksi yeşil alglerden olan Mougeotia sp. araştırma alanımızdaki bütün göllerde rastlanmıştır. Mougeotia cinsine ait türlerin oligomezotrofik ortamlarda dominant olabildiği bilinmektedir (Salmaso, 2000).

\section{KAYNAKÇA}

Akköz, C. \& Güler, S. (2004). The Algal Flora of Topçu Lake (Yozgat) I: Epilithic and Epiphytic Algae. (in Turkish with English abstract). Selçuk University Journal of Science Faculty, 23: 7-14.

Albay, M., Akcaalan, R., Aykulu, G., Tufekci, H., Beattie, KA. \& Codd, G.A. (2003). Occurrence of toxic cyacobacteria before and after cupper sulphate treatment in a water reservoir, Istanbul, Turkey. Algological Studies, 109:67-78. doi: 10.1127/1864-1318/2003/0109-0067

Anonim, (1999). The MOLAR project: atmospheric deposition and lake water chemistry. Journal of Limnology, 58: 88-106.

Aykulu, G., Obalı, O. \& Gönülol, A. (1983). The distribution of the phytoplankton of some lakes of Ankara around (in Turkish with English abstract). Doğa Bilim Dergisi, 7: 277-288.

Aysel, V. (2005). Check-List of The Freshwater Algae of Turkey. Journal of Black Sea/Mediterranean Environment, 11(1): 5-128.

Balık, S., Ustaoğlu, M.R. \& Özbek, M. (2003). The Mollusc fauna of some lakes on Taurus Mountains (S Anatolia) (in Turkish with English abstract). Ege Journal of Fisheries and Aquatic Sciences, 20: 351-355.
Wetzel (1975)'in daha çok organik maddece zengin sığ sularda bulunduğunu bildirdiği Euglenophyta bölümü üyeleri, Kartal Gölü hariç araştırılan diğer göllerde saptanmıştır. Araştırma alanında tespit edilen Lepocinclis acus, L. oxyuris, Phacus tortus türleri ülkemizde yer alan mezotrofik veya ötrofik karakterli iç su ekosistemlerinde yaygın olarak bulunmaktadır (Cirik-Altındağ, 1983; Kılınç, 1998, Ersanlı ve Gönülol, 2003).

Ochrophyta sınıfından Dinobryon cinsine ait 3 takson Gökçeova Göleti ve Karagöl'de tespit edilmiştir. Dinobryon türlerinin besin azlığının yaşandığı durumlarda bakterilerle beslenen ve miksotrofik davranışlar sergileyen oligotrofik ortamlara özgü organizmalar olduğu bilinmektedir (Isaksson, 1998). Bu cinse ait taksonlar ülkemizdeki oligotrofik veya mezotrofik karakterli göl ve barajlardan bildirilmiştir (Naz ve Türkmen, 2005; Taş ve Gönülol, 2007; Çelekli vd., 2007; Özyalın ve Ustaoğlu, 2008).

Dinoflagellatlardan ise 3 takson tespit edilmiştir. Bunlardan araştırma alanındaki Saklıgöl, Gökçeova Göleti ve Kartal Gölü'nde saptanan $P$. cunningtonii ülkemizdeki mezotrofik veya ötrofik karakterli iç su ekosistemlerinde de bulunmaktadır (Sömek vd., 2005; Ongun-Sevindik, 2010).

Göllerin fitoplankton kompozisyonunda oligotrof ve mezotrof göllerde rastlanılan belirteç türlerin birlikte bulunması ve TDİ değerleri dikkate alındığında, çalışılan göllerin verimlilik durumunun halen oligotrofik olmakla birlikte, mesotrofik duruma doğru bir geçiş eğiliminde olduğu söylenebilir. Ancak bu göllerin verimlilik durumlarının kesin olarak tespit edilebilmesi için, fitoplankton kompozisyonu ve diğer çevresel parametrelerin en az bir yıl boyunca incelenmesine intiyaç vardır.

\section{TEŞEKKÜR}

Bu çalışmayı finansal açıdan destekleyen Ege Üniversitesi Bilimsel Araştırma Projeleri Şube Müdürlüğüne (BAP Proje No: 2009/SÜF/002) teşekkür ederiz.

Baykal, T., Açıkgöz, İ., Yıldız, K. \& Bekleyen, A. (2004). A Study on Algae in Devegeçidi Dam Lake. Turkish Journal of Botany, 28: 457-472.

Bourrelley, P. (1966). Les Algues d'eau douce. Initiation á la systématique. Tome 1: Les Algues Vertes. Paris, Boubée éd., 1-511, 117 pl.

Bourrelley, P. (1968). Les Algues d'eau douce . Initiation á la systématique. Tome 2: Les Algues jaunes et brunes. Chrysophycées, Phéophycées, Xanthophycées et Diatomées. Paris, Boubée éd., 1-438, 114 pl., 1 tabl.

Bourrelley, P. (1970). Les Algues d'eau douce . Initiation á la systématique. Tome 3: Les Algues bleues et rouges. Les Eugléniens, Péridiniens et Cryptomonadines. Paris, Boubée éd., 1-512, $137 \mathrm{pl}$.

Bozniak, E.G. \& Kenedy, L.L. (1968). Periodicity and Ecology of the Phytoplankton in an Oligotrophic and Eutrophic Lake. Canadian Journal of Botany, 46, 1259-1275. doi: 10.1139/b68-168

Carlson, R.E. (1977). A trophic state index for lakes. Limnology and Oceanography. 22:361-369.

Carlson, R.E. \& J. Simpson. (1996). A Coordinator's Guide to Volunteer Lake Monitoring Methods. North American Lake Management Society. 96 pp. 
Cigagna, C., Bonotto, D.M., Camargo, A.F.M. \& Sturaro, J.R. (2016). Trophic state index (TSI) and physico-chemical characteristics of a shallow reservoir in southeast Brazil. Environmental Earth Sciences, 75 (2), art. no. 102, pp. 1-11. doi: 10.1007/s12665-015-4951-0

Cirik S. \& Cirik S. (1989). Planctonic algae of Gölcük (Bozdağ/lzmir) (in Turkish). İstanbul University Journal of Aquatic Products 3: 131-150.

Cirik-Altındağ, S. (1982). Phytoplankton of Manisa-Marmara Lake, ICyanophyta (in Turkish with French abstract). Doğa Bilim Dergisi, 6 (3): 67-81.

Cirik-Altındağ, S. (1983). Phytoplankton of Manisa-Marmara Lake, IIEuglenophyta, (in Turkish with French abstract). Doğa Bilim Dergisi, 7 460-468.

Celekli, A., Albay, M. \& Dügel, M. (2007). Phytoplankton (excep Bacillariophyceae) Flora of Lake Gölköy (Bolu). Turkish Journal of Botany, 31:49-65.

Ersanlı, E. \& Gönülol, A. (2003). Study on the Phytoplankton and Seasonal Variation of Lake Simenit (Terme-Samsun, Turkey), Turkish Journal of Fisheries and Aquatic Sciences, 3: 29-39.

Gönülol, A. \& Obalı, O. (1998). A study on the Phytoplankton of Hasan Uğurlu Dam Lake (Samsun-Turkey). Turkish Journal of Biology, 22: 447-462.

Guiry, M.D. \& Guiry, G.M. (2016). AlgaeBase. World-wide electronic publication, National University of Ireland, Galway. http://www.algaebase.org; searched on 07 March 2016.

Heinonen, P. (1980). Quantity and composition of phytoplankton in Finnish inland waters. Publ. Water Res. Inst. 37, Vesihallitus-National Board of Waters, Finland.

Hustedt, F. (1930). Bacillariophyta Diatome Heft: 10 A Pascher DieSusswasse Flore Mitteleuropas. Ed. Gustav Fischer Pub., Jena, 466p, Germany.

Hutchinson, G.E.A. (1957). Treatise on Limnology Volum I: Geopraphy, Physics and Chemistry, John Wiley, Newyork.

Isaksson, A. (1998). Phagotrophic phytoflagellates in lakes. A literature review. In: Archiv für Hydrobiologie, Special Issues: Advances in Limnology, 51 63-90.

Isşbakan-Taş, B., Gönülol, A. \& Taş, E. (2002). A Study on the Seasonal Variation of the Phytoplankton of Lake Cernek (Samsun-Turkey). Turkish Journal of Fisheries and Aquatic Sciences, 2: 121-128.

John, D.M., Whitton, B.A. \& Brook, A.J. (2003). The Freshwater Algal Flora of the British Isles: An Identification Guide to Freshwater and Terrestria Algae. Cambridge University Press. New York. 701 pages.

Karacaoğlu, D., Şukran D. \& Dalkıran, N. (2004). A Taxonomic Study on the Phytoplankton of Lake Uluabat (Bursa). Turkish Journal of Botany, 28: 473-485.

Katip, A., lleri, S., Karaer, F. \& Onur, S. (2015). Determination of the Trophic State of Lake Uluabat (Bursa-Turkey). Ekoloji, 24, 97, 24-35. doi: 10.5053/ekoloji.2015.07.

KIIInç, S. (1998). A Study in The Seasonal Variation of Phytoplankton in Hafik Lake (Sivas, Turkey), Turkish Journal of Botany, 22:35-41.

Kıvrak, E. \& Gürbüz, H. (2005). Seasonal variations in phytoplankton composition and physical-chemical features of Demirdöven Dam Reservoir, Erzurum, Turkey. Biologia, Bratislava, 60/1: 1-8.

Kolayll, S. \& Sahin, B. (2007). A Taxonomic Study on the Phytoplankton in the Littoral Zone of Karagöl Lake (Borçka-Artvin/Turkey). Turkish Journal of Fisheries and Aquatic Sciences, 7: 171-175.

Komárek, J. \& Zapomelova E. (2007). Planktic morphospecies of the cyanobacterial genus Anabaena = subg. Dolichosperumum-1. part: coiled types. Fottea 7: 1-31.

Lampert, W. \& Sommer, U. (2007). Limnoecology: The Ecology of Lakes and Streams. 2nd edition. Oxford: Oxford University Press, 324 pp. ISBN ISBN-13: 9780199213931.

Legnerova, J. (1965). The Genera Ankistrodesmus Corda and Raphidium Kützing and their Position in the Family Ankistrodesmusmaceae. Preslia $37: 1-8$
Naz, M. \& Türkmen, M. (2005). Phytoplankton biomass and species composition of Lake Gölbaşı (Hatay-Turkey). Turkish Journal of Biology, 29: 49-56.

Ongun-Sevindik, T. (2010). Phytoplankton Composition of Caygören Reservoir, Balikesir-Turkey. Turkish Journal of Fisheries and Aquatic Sciences 10: 295-304.

Özyalın, S. \& Ustaoğlu M.R. (2008). Investigation of the net phytoplankton composition of Kemer Impoundment (Aydın) (in Turkish with English abstract). Ege Journal of Fisheries and Aquatic Sciences, 25 (4): 275-282.

Palmer, C.M. (1980). Algae and Water Pollution, Castle House Pub., London.

Pechlaner, R. (1971). Factors that control the production rate and biomass of phytoplankton in high-mountain lakes. Verhandlungen Internationale Vereinigung für theoretische und angewandte Limnologie 19, 125-145.

Philipose, M. T. (1967). Chlorococcales. I. C. A. R., New Delhi, 365 p.

Reynolds, C.S., Huszar, V., Kruk, C., Naselli-Flores, L. \& Melo, S. (2002). Rewiew, Towards A Functional Classification of the Freshwater Phytoplankton. Journal of Plankton Research, 24(5): 417-428. doi: 10.1093/plankt/24.5.417

Round, F. E. (1973). The Biology of the Algae, Edward Arnold, London.

Sakamoto, M. (1966). The Chlorophyll Amount In The Euphotic Zone In Some Japanese Lakes and Its Significace In Thr Photosynthetic Production of Phytoplankton Community. Bot. Mag. Tokyo, 79: 77-78.

Salmaso, N. (2000). Factors affecting the seasonality and distribution of cyanobacteria and chlorophytes: a case study from the large lakes south of the Alps, with special reference to Lake Garda. Hydrobiologia, 438: 4363.

Sarı, D. (2010). Biyoçeşitlilik ve floristik çeşitlilik açısından alpin alanların önemi. III. Ulusal Karadeniz Ormancllık Kongresi, Cilt: IV Sayfa: 1447-145.

Sims, P.A. (1996). An Atlas of British Diatoms. Illustrated by Horace G. Barber, \& John R. Carter, arranged by Bernard Hartley. Biopress Ltd., Bristol, United Kingdom. $601 \mathrm{pp}$

Sömek, H. \& Balık, S. (2009). Seasonal variation of Algal flora and Environmental conditions of Karagöl (A Mountain Lake, Izmir-Turkey) (in Turkish with English abstract). Ege Journal of Fisheries and Aquatic Sciences, 26(2): 121-128.

Sömek, H., Balık, S. \& Ustaoğlu M.R. (2005). Phytoplankton of Topçam Dam Lake (Çine-Aydın) and Their Seasonal Variations (in Turkish with English abstract). Süleyman Demirel University Eğirdir Journal of Fisheries Faculty, 1(1): 26-32.

Şahin, B. (2000). Algal flora of lakes Aygır and Balıklı (Trabzon, Turkey), Turkish Journal of Botany, 24: 35-45.

Şahin, B. (2001). Epipelic and epilithic algae of Dağbaşı lake (Rize-Turkey). Turkish Journal of Botany, 25: 187-194.

Şahin, B. \& Akar, B. (2007). The Desmid Flora of Some High Mountain Lakes of the Turkish Eastern Black Sea Region. Pakistan Journal of Botany, 39(5): 1817-1832, 2007.

Şen, B., Çağlar, M. \& Toprak Pala, G. (2001). The Diatoms of Tadım Pond (Elazığ) and Their Seasonal Distrubition (in Turkish with English abstract). Science and Engineering Journal of Firat University, 13 (2): 255-261.

Taş, B. \& Gönülol, A. (2007). Planktonic algae of Derbent Dam Lake (Samsun, TURKEY). Journal of FisheriesSciences.com,1 (3): 111-123.

Tolotti, M. (2001). Phytoplankton and littoral epilithic diatoms in high mountain lakes of the Adamello-Brenta Regional Park (Trentino, Italy) and their relation to trophic status and acidification risk. Journal of Limnology, 60 (2): 171-188. doi: 10.4081/jimnol.2001.1.171

Ustaoğlu, M. R., Balık, S., Özdemir Mis, D. \& Aygen, C. (2005). The Zooplankton of Some Lakes in the Taurus Range (Turkey). Zoology in the Middle East, 34: 101-108.

Ustaoğlu, M.R., Balık, S. \& Özbek, M. (2004). Contributions to the Knowledge of Malacostraca (Crustacea) Fauna of the Taurus Mountains District (Southern Anatolia). Turkish Journal of Zoology, 28:91-94. 
Vaitomaa, J. (2006). The effects of environmental factors on biomass and microcystin production by the freshwater cyanobacterial genera Microcystis and Anabaena. Edita, Helsinki, Finland, $56 \mathrm{p}$.

Vollenweider R.A. \& Kerekes J.J. (1982). Eutrophication of waters. Monitoring assessment and control. OECD Cooperative programme on monitoring of inland waters (Eutrophication control), Environment Directorate, OECD, Paris. $154 \mathrm{p}$.

Wetzel, R.G. (1975). Limnology. W,B. Sounders Conpany, Phiadelphia, 743p.
Willén, E., Hajdu, S. \& Pejler, Y. (1990). Summer phytoplankton in 73 nutrientpoor Swedish lakes - classification, ordination and choice of long-term monitoring objects. Limnologica, 20: 217-227.

Yıldız, S., Özbek, M., Ustaoğlu, M.R. \& Sömek, H. (2012). Distribution Patterns of Aquatic Oligochaetes (Annelida, Clitellata) in the Eastern Black Sea Range of Turkey. Turkish Journal of Zoology, 36(1): 59-74.

Yıldız, S., Taşdeir, A., Özbek, M., Balık, S. \& Ustaoğlu, M.R. (2005). Macrobenthic Invetebrate Fauna of Lake Eğrigöl (Gündoğmuş-Antalya). Turkish Journal of Zoology, 29: 275-282. 